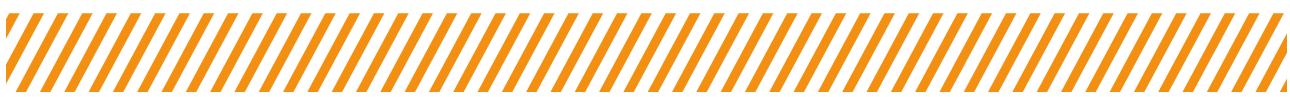

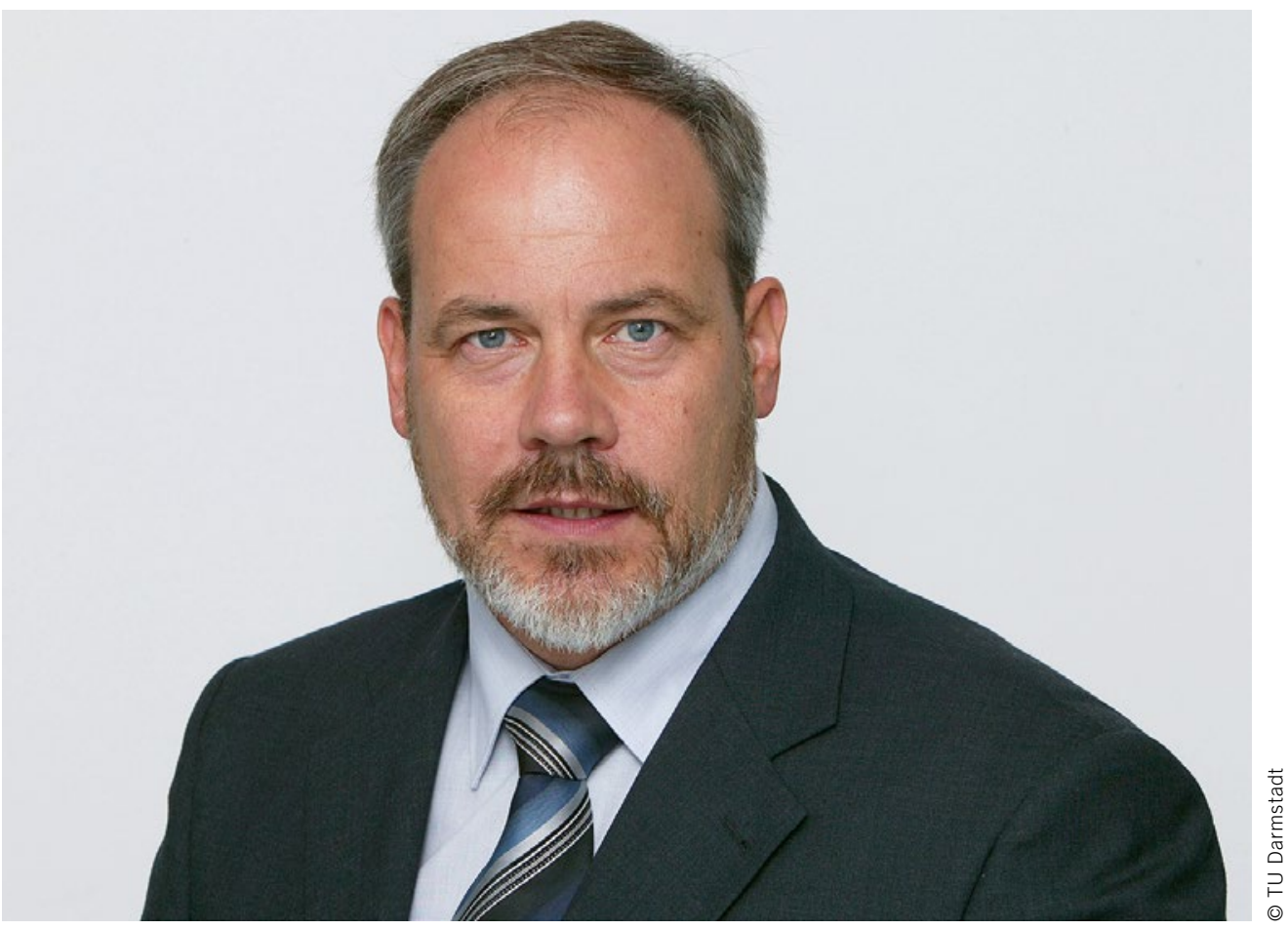

Prof. Dr. Christian Beidl Leiter des Instituts für Verbrennungskraftmaschinen und Fahrzeugantriebe, Technische Universität Darmstadt

\section{Plug-in-Hybride glaubhaft positionieren}

Plug-in-Hybrid-Antriebe sind grundsätzlich eine feine Sache. Dennoch werden kritische Stimmen laut - Stimmen, die ich für bedenklich und diskussionswürdig halte.

Der unbestrittene Vorteil dieser Hybridvariante gegenüber batterieelektrischen Fahrzeugen ist die größere Reichweite. Bei entsprechender elektrischer Aufladung kann, laut Statistik, der überwiegende Teil der täglichen Fahrstrecken emissionsfrei gefahren werden. Die optimale Ausnutzung der mitgeführten elektrischen Energie in Kombination mit dem breiten Einsatzspektrum der Fahrzeuge steht für viele elektrisch gefahrene Kilometer. Dies rechtfertigt ihre Einstufung als Elektrofahrzeug. Zudem bleiben auch im kombinierten Betrieb signifikante Emissions- und Verbrauchsvorteile. Das klingt nach einer perfekten Lösung.

Und die kritischen Stimmen? Geht man auf Ursachenforschung, so stellt man fest, dass die Motivation der beteiligten Interessensgruppen sehr unterschiedlich ausfällt. Für Politik und Gesellschaft ist der Plug-in-Hybrid eine Brückentechnologie, die der Elektromobilität zum Durchbruch verhelfen sollte. Es wurde ein Testverfahren definiert, in dem für die elektrischen Fahranteile keine $\mathrm{CO}_{2}$-Emission berücksichtigt wird - ein guter Anreiz. Damit ist es durch entsprechende Skalierung der Batteriegröße einfach möglich, auch für große Fahrzeuge nominelle $\mathrm{CO}_{2}$-Emissionswerte unter $50 \mathrm{~g} / \mathrm{km}$ und entsprechend niedrige Verbrauchsangaben zu erreichen. Dies wiederum hilft den OEMs, die künftigen Flottenemissionsziele einzuhalten.
Scheinbar ideal - wären da nicht die Kosten. Bedingt durch die relativ kleinen Stückzahlen und den Anspruch, die Kunden auf keinen Fall zu enttäuschen, werden die verfügbaren konventionellen Antriebsmodule um leistungsfähige elektrische Komponenten erweitert. Zwei vollständige Antriebe treiben Kosten und Gewicht nach oben. Damit ist der Markteinführungsweg über die Premiumschiene vorgezeichnet, was ich ebenfalls für bedenklich halte.

Mit grünem Image könnte man zwar durchaus starten, aber spätestens wenn für schwere SUVs oder Sportwagen Verbrauchswerte unter $2 \mathrm{l}$ angegeben werden, drängt sich der Verdacht einer Mogelpackung auf. Dabei liegt es allein in der Hand des Nutzers, ob er diesen Wert erreicht oder unterschreitet.

Das vorgegebene Schema der Verbrauchsangabe passt einfach nicht und ist schwer zu vermitteln. Also bleibt nur noch die Positionierung über Premiumfahrleistungen. Dahinter steckt auch Zündstoff. Denn wenn Fahrspaß die primäre Motivation ist, wird der Kunde dann den Zusatzaufwand des elektrischen Aufladens auf sich nehmen - für ein paar elektrische Kilometer mehr? Zudem darf die gesellschaftliche Akzeptanz für Luxusfahrzeuge auf Gratisparkplätzen bezweifelt werden.

Die Herausforderung ist demzufolge groß. Wir brauchen mehr und leistbare Lösungen - und zwar dezidiert für die Volumensegmente. Eine glaubhafte Kommunikation ist jetzt von Nöten. Dann sind Plug-in-Hybride wirklich eine feine Sache. 